
пилотного этапа амбулаторного регистра «РЕГИОН»

\author{
Сергей Анатольевич Бойцов ${ }^{1}$, Михаил Михайлович Лукьянов 1*, \\ Сергей Степанович Якушин², Сергей Юрьевич Марцевич1, \\ Людмила Витальевна Стаховская3 , Александр Николаевич Воробьев2, \\ Александр Васильевич Загребельный1, Александр Николаевич Козминский², \\ Ксения Анатольевна Мосейчук², Кристина Геннадьевна Переверзева2, \\ Екатерина Алексеевна Правкина2, Екатерина Николаевна Белова1, \\ Владислав Георгиевич Кляшторный1, Егор Викторович Кудряшов 1 , \\ Елена Юрьевна Окшина1, Александр Дмитриевич Деев 1 \\ 1 Государственный научно-исследовательский центр профилактической медицины \\ Россия, 101990, Москва, Петроверигский пер., 10 \\ 2 Рязанский государственный медицинский университет имени академика И.П. Павлова \\ Россия, 390026, Рязань, ул. Высоковольтная, 9 \\ з Российский национальный исследовательский медицинский университет им. Н. И. Пирогова \\ Россия, 117997, Москва, ул. Островитянова, 1
}

\begin{abstract}
Цель. Оценить медикаментозное лечение больных, перенесших острое нарушение мозгового кровообращения (ОНМК), в рамках проспективных амбулаторных регистров.

Материал и методы. В амбулаторный регистр больных, перенесших ОНМК любой давности (регистр ОНМК-лД), а также в амбулаторный регистр первого обращения (ОНМК-ПО) в поликлинику после перенесенного мозгового инсульта на базе одной из поликлиник г. Рязани были включены в рамках пилотного этапа, соответственно, 200 и 115 пациентов. В ходе проспективного наблюдения оценены соответствие назначенной и реально принимаемой медикаментозной терапии клиническим рекомендациям, ее преемственность, а также приверженность пациентов лечению.

Результаты. На амбулаторном этапе, особенно в период до референсного ОНМК, большинство больных не получало адекватной терапии для снижения риска развития ОНМК и других сердечно-сосудистых осложнений. В регистре ОНМК-ПО, по сравнению с регистром ОНМКЛД (в нем дата развития ОНМК была в среднем на 4,8 года раньше), в постинсультном периоде значимо чаще $(p<0,05)$ назначались лекарственные препараты с доказанным благоприятным действием на прогноз (в т.Ч. статины при ОНМК - 46,9\% по сравнению с $11 \%$; статины при ишемической болезни сердца (ИБС) - 43\% и 10,3\%; антиагреганты при ИБС без фибрилляции предсердий - 57,7\% и 27\%, антикоагулянты при фибрилляции предсердий - 17,6\% и 2,3\%). Через 3 года наблюдения в регистре ОНМК-ЛД и 2 года - в регистре ОНМК-ПО частота принимаемой терапии значимо не отличалась от частоты назначений на этапе включения в регистры, за исключением статинов (их принимали в 1,7 и 1,5 раз реже). Прогностически значимые назначения этапа включения выполнялись в отдаленном периоде наблюдения в 49\% и 70\% случаев (в среднем 58\%), соответственно, однако частота впервые назначенной терапии составила 44\% и $19 \%$ от общего числа назначений в данном периоде, соответственно. Согласно опроснику Мориски-Грина приверженными лечению были 17,7 и 51,7\% пациентов, соответственно.

Заключение. Результаты пилотного этапа исследования РЕГИОН (амбулаторные регистры ОНМК-ЛД и ОНМК-ПО) показали, что качество назначенной медикаментозной терапии пациентов в поликлинике является недостаточным. Сравнение данных регистров ОНМК-ЛД и ОНМКПО позволяет сделать предварительный вывод о том, что за 5-летний период, разделяющий давность развития ОНМК в этих регистрах, качество лечения пациентов значительно улучшилось, хотя и в недостаточной степени. На этапе отдаленного проспективного наблюдения доля выполнения сделанных ранее прогностически значимых назначений составила в среднем лишь около 60\%. В целом за время наблюдения, с учетом вновь сделанных назначений частота проведения должной медикаментозной терапии снизилась только по отношению к приему статинов. По данным опросника Мориски-Грина большинство пациентов было недостаточно привержено медикаментозному лечению.
\end{abstract}

Ключевые слова: острое нарушение мозгового кровообращения, мозговой инсульт, транзиторная ишемическая атака, амбулаторный регистр, оценка соответствия медикаментозной терапии клиническим рекомендациям, проспективное наблюдение, приверженность лечению.

Для цитирования: Бойцов С.А., Лукьянов М.М., Якушин С.С., Марцевич С.Ю., Стаховская Л.В., Воробьев А.Н., Загребельный А.В., Козминский А.Н., Мосейчук К.А., Переверзева К.Г., Правкина Е.А., Белова Е.Н., Кляшторный В.Г., Кудряшов Е.В., Окшина Е.Ю., Деев А.Д. Медикаментозное лечение больных, перенесших острое нарушение мозгового кровообращения: данные пилотного этапа амбулаторного регистра «РЕГИОН». Рациональная фармакотерапия в кардиологии 2017;13(3):346-356. DOI: http://dx.doi.org/10.20996/1819-6446-2017$13-3-346-356$ 


\section{Drug Treatment of Patients with the History of Acute Stroke: Data of the Pilot Phase of the Outpatient Registry «REGION »}

Sergey A. Boytsov1, Michail M. Loukianov1*, Sergey S. Yakushin2, Sergey Yu. Martsevich1, Lyudmila V. Stakhovskaya², Alexander N. Vorobyev², Alexander V. Zagrebelnyy1, Alexander N. Kozminsky22, Ksenia A. Moseichuk², Kristina G. Pereverzeva2, Ekaterina A. Pravkina², Ekaterina N. Belova1, Vladislav G. Klyashtorny1, Egor V. Kudryashov1, Elena Yu. Okshina1, Alexander D. Deev

1 State Research Centre for Preventive Medicine. Petroverigsky per. 10, Moscow, 101990 Russia

2 I.P. Pavlov Ryazan State Medical University. Vysokovoltnaya ul. 9, Ryazan, 390026 Russia

3 Pirogov Russian National Research Medical University. Ostrovitianova ul. 1, Moscow, 117997 Russia

Aim. To study the pharmacological treatment of patients with acute stroke (AS) within the prospective outpatient registries.

Material and methods. In the pilot phase of the study, conducting on the base of one of the out-patient clinic in Ryazan city, 200 and 115 patients were included into the outpatient registry of patients with AS history of any remoteness (AS-AR registry), and outpatient registry of the first apply (ASFA registry) to the out-patient clinic after stroke, respectively. The correspondence of the prescribed and actually taken drug therapy to clinical recommendations, its continuity, and the adherence of patients to treatment were assessed during the prospective observation.

Results. Most patients did not receive adequate therapy to reduce the risk of AS and other cardiovascular complications in the outpatient stage, especially in the period prior to the reference AS. Drugs with a proven beneficial effect on the prognosis in the post-stroke period were prescribed significantly $(p<0.05)$ more frequently in the AS-FA registry compared to the AS-AR registry (date of stroke was an average of 4.8 years earlier), including: statins for AS $-46.9 \%$ vs $11 \%$; statins for ischemic heart disease $-43 \%$ vs $10.3 \%$, antiplatelet agents for ischemic heart disease without atrial fibrillation $-57.7 \%$ vs $27 \%$, anticoagulants in atrial fibrillation $-17.6 \%$ vs $2.3 \%$, respectively. After 3 years of observation in the AS-AR registry and after 2 years - in the AS-FA registry, the frequency of the therapy was not significantly different from the frequency of prescribing at the stage of inclusion in the registers, with the exception of statins (they were taken 1.7 and 1.5 times less frequently). Prognostically significant prescriptions of the inclusion phase were performed in the long-term follow-up period in $49 \%$ and $70 \%$ of patients (on average $58 \%$ ), respectively; however, the frequency of first-time therapy was $44 \%$ and $19 \%$ of the total number of prescriptions in this period, respectively. Adherence to treatment, according to the Morisky-Green questionnaire, was revealed in 17.7 and $51.7 \%$ of patients, respectively

Conclusion. The results of the pilot phase of the REGION study (AS-AR and AS-FA outpatient registries) showed that the quality of the prescribed drug therapy of patients in out-patient clinic is inadequate. A comparison of the data of AS-AR and AS-FA registries allows to make a preliminary conclusion that over the 5 -year period separating the remoteness of AS development in these registries, the quality of patient treatment has significantly improved, although not enough. The proportion of previously performed prognostically significant prescriptions averaged only about $60 \%$ at the stage of the further prospective follow-up. In general, during the observation period, taking into account newly made prescriptions, the frequency of adequate drug therapy during the observation period decreased only for statins. Most patients were not sufficiently committed to pharmacological treatment according to the Morisky-Green questionnaire.

Keywords: acute cerebrovascular accident, cerebral stroke, transient ischemic attack, outpatient registry, assessment of compliance of drug therapy with clinical recommendations, prospective observation, adherence to treatment.

For citation: Boytsov S.A., Loukianov M.M., Yakushin S.S., Martsevich S.Y., Stakhovskaya L.V., Vorobyev A.N., Zagrebelnyy A.V., Kozminsky A.N., Moseichuk K.A., Pereverzeva K.G., Pravkina E.A., Belova E.N., Klyashtorny V.G., Kudryashov E.V., Okshina E.Y, Deev A.D. Drug Treatment of Patients with the History of Acute Stroke: Data of the Pilot Phase of the Outpatient Registry «REGION». Rational Pharmacotherapy in Cardiology 2017;13(3):346-356. (In Russ). DOI: 10.20996/1819-6446-2017-13-3-346-356

*Corresponding Author (Автор, ответственный за переписку): loukmed@gmail.com

Received / Поступила: 08.06.2017

Accepted / Принята в печать: 13.06.2017

Мозговой инсульт (МИ), который, наряду с транзиторной ишемической атакой (ТИА) входит в понятие острого нарушения мозгового кровообращения (ОНМК), является второй по частоте причиной смертности от болезней системы кровообращения после инфаркта миокарда (ИМ) и основной причиной инвалидизации населения в мире [1]. Несмотря на совершенствование системы оказания медицинской помощи больным с OHMК, заболеваемость и смертность от МИ в Российской Федерации остаются одними из самых высоких в мире, значительно превышая данные показатели в странах с наиболее развитыми экономикой и здравоохранением [2].

Эффективные меры первичной профилактики ОНМК позволяют предотвратить часть случаев этого грозного сердечно-сосудистого осложнения [3,4]. Вто- ричная профилактика ОНМК, прежде всего, медикаментозная терапия с доказанным благоприятным действием на прогноз, способна существенно снизить как частоту повторного МИ, так и связанную с ним сердечнососудистую смертность [4-6]. Основные положения первичной и вторичной профилактики МИ сформулированы в ряде современных клинических рекомендаций [3-9].

Эффективность вторичной профилактики ОНМК у больных сердечно-сосудистыми заболеваниями (СС3), влияние проводимого лечения на прогноз в значительной степени определяются эффективностью мер по достижению целевого уровня артериального давления и показателей липидного профиля крови, качеством лечения таких наиболее распространенных и прогностически значимых СС3, как артериальная гипертония 
(АГ), ишемическая болезнь сердца (ИБС), хроническая сердечная недостаточность (XCH), фибрилляция предсердий (ФП) $[4-7,10,11]$.

Несмотря на то, что в ряде стран, в т.ч. в России, были организованы исследования по изучению проблемы МИ в медицинской практике [12-16], существует необходимость детального и комплексного изучения качества медикаментозной терапии данной категории больных на амбулаторном этапе, в т.ч. в динамике и с учетом наличия у них сочетанных сердечно-сосудистых и сопутствующих заболеваний. Важной причиной этого является то, что реальная клиническая практика лишь в малой степени соответствует тому, что сформулировано в клинических рекомендациях [12-19].

Регистры СС3, в частности, регистры ОНМК представляют наиболее объективные данные о медицинской практике, ее особенностях в различных регионах или медицинских учреждениях. Однако имеющихся результатов отдельных регистров больных, перенесших OHMK $[15,16,19-24]$, недостаточно для оценки качества медикаментозного лечения, его динамики в ходе проспективного наблюдения данной категории больных в амбулаторно-поликлинической практике в Российской Федерации [25-27].

Таким образом, представляется весьма важным в рамках амбулаторного регистра больных, перенесших ОНМК, оценить качество их медикаментозного лечения в реальной медицинской практике.

Цель данной работы - оценить медикаментозное лечение больных, перенесших ОНМК и включенных в проспективные амбулаторные регистры, в рамках исследования РЕГИОН.

В данной публикации существенно дополнены представленные ранее первые результаты амбулаторных регистров в г. Рязани, являющихся составной частью этого исследования [28].

\section{Материал и методы}

Два амбулаторных регистра больных, перенесших ОНМК (МИ/ТИА), созданы на базе 3-х поликлиник г. Рязани. Эти регистры являются составной частью исследования РЕГИОН (РЕГИстр больных, перенесших Острое Нарушение мозгового кровообращения), проводящегося в г. Москве и в г. Рязани.

В регистр больных, перенесших ОНМК любого срока давности (регистр ОНМК-ЛД), запланировано включение около 500 (но не менее 450) пациентов, перенесших ОНМК любой давности до обращения в три поликлиники г. Рязани, соответственно в марте-мае 2012 г., сентябре-октябре 2012 г. и январе-феврале 2013 г.

В регистр больных, впервые обратившихся в поликлинику после перенесенного ОНМК (регистр ОНМКПО), будет включено около 500 (но не менее 450) па- циентов, впервые обратившихся в три поликлиники г. Рязани в 2013-2015 гг. после перенесенного ОНМК.

Более подробное описание дизайна исследования было представлено нами в предшествующих публикациях $[27,28]$. В данной публикации результатов пилотного этапа представлен анализ данных о назначенной и реально принимаемой терапии у всех пациентов, обратившихся в одну из поликлиник г. Рязани за период январь 2013 г.- июнь 2015 г. и включенных в регистры ОНМК-ЛД и ОНМК-ПО.

На этапе проспективного наблюдения оценка принимаемой медикаментозной терапии, приверженности лечению у пациентов, включенных в регистры, проводилась путем опроса выживших при телефонном контакте или визите в течение апреля-июля 2016 г. Информацию о принимаемой медикаментозной терапии удалось установить у 193 (96,5\%) и $112(97,4 \%)$ человек, в регистрах ОНМК-ЛД и ОНМК-ПО, соответственно. Данные о медикаментозном лечении 7-ми (3,5\%) и 3-х (2,6\%) пациентов получить не удалось. В случае наличия у больных выраженных когнитивных нарушений контакт осуществлялся с их родственниками. Для оценки приверженности медикаментозному лечению использовался опросник Мориски-Грина [29].

Для статистической обработки данных применялся пакет статистических программ SPSS Statistics 20.0 ( IBM $^{\circledR}$, CША). При анализе результатов пилотного этапа использовались стандартные методы описательной статистики. Достоверность различий частоты наличия признака между группами сравнения определялась непараметрическим методом с использованием критерия хи-квадрат. При оценке статистической значимости различий частоты назначения лекарственных препаратов на этапах включения и проспективного наблюдения применяли тест Мак-Немара.

\section{Результаты}

Данные о назначенной и принимаемой медикаментозной терапии были оценены в рамках пилотного этапа исследования у 200 пациентов, включенных в регистр ОНМК-ЛД, а также у 115 человек, включенных в регистр ОНМК-ПО.

Средний возраст пациентов, включенных в регистры ОНМК-ЛД и ОНМК-ПО, составил 71,2 $\pm 10,7$ и $71,4 \pm 11,1$ лет, число мужчин - 82 (41\%) и 50 $(43,5 \%)$. По возрастным и гендерным характеристикам, структуре сердечно-сосудистых и сопутствующих заболеваний не было значимых различий между регистрами. Исключение составили более высокая частота хронических болезней почек и ТИА в анамнезе у пациентов регистра ОНМК-ЛД. Подробная характеристика больных, включенных в регистры на пилотном этапе, была опубликована нами ранее [28]. 
Table 1. The frequency of prognosis-modifying drug prescriptions for cardiovascular diseases before the development of reference acute stroke in patients included in the registries (\%)

Таблица 1. Частота прогноз-модифицирующих медикаментозных назначений по поводу СС3 до развития референсного ОНМК у больных, включенных в регистры (\%)

\begin{tabular}{|c|c|c|}
\hline Группа ЛП и показания к их назначению & Регистр ОНМК-лД (n=200) & Регистр ОНМК-ПО (n=115) \\
\hline ИАПФ/БРА при ХСН & 29,6 & $57,1^{*}$ \\
\hline ИАПФ при ПИКС & 25,7 & 39,1 \\
\hline 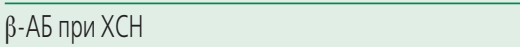 & 15,1 & $33,7^{*}$ \\
\hline 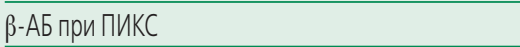 & 20,0 & 39,1 \\
\hline Статины при ИБС & 8,4 & $25,6^{*}$ \\
\hline Статины при ПИКС & 11,4 & 26,1 \\
\hline Статины при ОНМК в анамнезе & $8,8(n=34)^{a}$ & $13,0(n=23)$ a \\
\hline Антикоагулянты при ФП & 9,0 & 14,7 \\
\hline Антиагреганты при ИБС без ФП & 22,5 & $42,2^{*}$ \\
\hline Антиагреганты при ПИКС без ФП & 30,4 & 27,2 \\
\hline ИАПФ при ОНМК в анамнезе & $41,1(n=34)^{a}$ & $34,7(n=23)^{a}$ \\
\hline \multicolumn{3}{|l|}{ *р<0,05 по сравнению с регистром ОНМК-ЛД } \\
\hline \multicolumn{3}{|c|}{ ауказано число пациентов, у которых референсное ОНМК было повторным } \\
\hline \multicolumn{3}{|c|}{$\begin{array}{l}\text { ЛП - лекарственный препарат, ИАПФ - ингибиторы ангиотензинпревращающего фермента, БРА - блокаторы рецепторов ангиотензина, ХСН - хроническая сердечная недостаточность, } \\
\text { ПИКС - постинфарктный кардиосклероз, В-АБ - бета-адреноблокаторы, ИБС - ишемическая болезнь сердца, ОНМК - острое нарушение мозгового кровообращения, } \\
\text { ФП - фибрилляция предсердий }\end{array}$} \\
\hline
\end{tabular}

Table 2. The frequency of prognosis-modifying drug prescriptions for cardiovascular diseases in the first 6 months of observation in out-patient clinic after a reference acute stroke (\%)

Таблица 2. Частота прогноз-модифицирующих медикаментозных назначений по поводу СС3 в первые 6 мес наблюдения в поликлинике после референсного ОНМК (\%)

\begin{tabular}{|c|c|c|}
\hline Группа ЛП и показания к их назначению & Регистр ОНМК-ЛД $(n=200)$ & Регистр ОНМК-ПО (n=115) \\
\hline ИАПФ/БРА при ХСН & 32,2 & $57,1^{*}$ \\
\hline ИАПФ при ПИКС & 22,8 & 39,1 \\
\hline$\beta-А Б п р и ~ X С Н ~$ & 19,0 & $37,6^{*}$ \\
\hline$\beta-А Б$ при ПИКС & 28,5 & 39,1 \\
\hline Статины при ИБС & 10,3 & $43,0^{*}$ \\
\hline Статины при ПИКС & 17,1 & 34,8 \\
\hline Статиныа & 11,0 & $46,9 *$ \\
\hline Антикоагулянты при ФП & 2,3 & $17,6^{*}$ \\
\hline Антиагреганты при ИБС без ФП & 27,0 & $57,7^{*}$ \\
\hline Антиагреганты при ПИКС без ФП & 43,4 & 54,5 \\
\hline ИАПФа & 29,0 & $46,0^{*}$ \\
\hline \multicolumn{3}{|l|}{ *р<0,05 по сравнению с регистром ОНМК-ЛД } \\
\hline \multicolumn{3}{|c|}{ ауказана частота назначения для всех пациентов с ОНMК, включенных в регистры } \\
\hline \multicolumn{3}{|c|}{$\begin{array}{l}\text { ЛП - лекарственный препарат, ИАПФ - ингибиторы ангиотензинпревращающего фермента, БРА - блокаторы рецепторов ангиотензина, ХСН - хроническая сердечная недостаточность, } \\
\text { ПИКС - постинфарктный кардиосклероз, Р-АБ - бета-адреноблокаторы, ИБС - ишемическая болезнь сердца, ОНМК - острое нарушение мозгового кровообращения, } \\
\text { ФП - фибрилляция предсердий }\end{array}$} \\
\hline
\end{tabular}

Средняя продолжительность периода наблюдения в регистрах ОНМК-ЛД и ОНМК-ПО (до контакта

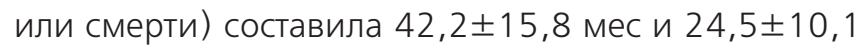
мес, что соответствует длительности 3,5 и 2,0 года. Важно отметить, что средняя продолжительность периода от развития ОНМК до референсного визита была 41 мес $(16 ; 83)$ и 19 сут (13; 30), т.е. 3,4 и 0,05 года. Дата референсного ОНМК в регистрах ОНМК-ЛД и ОНМКПО различалась в среднем на 4,8 года, что дало возможность сравнительной оценки динамики качества медикаментозного лечения больных с ОНMК за данный период.

Частота назначения основных групп лекарственных препаратов в первые 6 мес амбулаторного наблюдения после референсного ОНМК у больных регистров ОНМК-ЛД и ОНМК-ПО была кратко представлена нами ранее [28]. По данным более детального анализа в табл. 1 и 2 указана частота соответствия показаниям, влияющих на прогноз медикаментозных назначений по поводу ССЗ до и в течение первых 6 мес 
Table 3. Frequency of prognosis-modifying drug prescriptions for cardiovascular diseases in patients included in the acute stroke registry of any remoteness $(n=200)$

Таблица 3. Частота прогноз-модифицирующих медикаментозных назначений по поводу ССЗ у включенных в регистр больных, перенесших ОНМК любой давности $(\mathrm{n}=200)$

\begin{tabular}{|c|c|c|}
\hline $\begin{array}{l}\text { Группа ЛП и показания } \\
\text { к их назначениюа }\end{array}$ & $\begin{array}{c}\text { Назначения на амбулаторном этапе } \\
\text { за } 6 \text { мес после референсного ОНМК (\%) }\end{array}$ & $\begin{array}{c}\text { Назначения на амбулаторном этапе } \\
\text { на дату визита включения (\%) }\end{array}$ \\
\hline ИАПФ/БРА при ХСН (n=152) & 32,2 & $58,5^{*}$ \\
\hline ИАПФ при ПИКС ( $n=35)$ & 22,8 & 37,1 \\
\hline 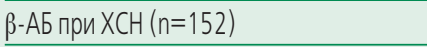 & 19,0 & $32,9 *$ \\
\hline$\beta-А Б$ при ПИКС (n=35) & 28,5 & 34,2 \\
\hline Статины при ИБС ( $n=154)$ & 10,3 & $427,2^{*}$ \\
\hline Статины при ПИКС (n=35) & 17,1 & 22,8 \\
\hline Статины при OHMK (n=200) & 11,0 & $25,5^{*}$ \\
\hline Антикоагулянты при ФП (n=44) & 2,3 & $13,6^{*}$ \\
\hline Антиагреганты при ИБС без ФП (n=111) & 27,0 & $51,3^{*}$ \\
\hline Антиагреганты при ПИКС без ФП (n=23) & 43,4 & 52,1 \\
\hline ИАПФ при ОНМК ( $n=200)$ & 29,0 & $46,5^{*}$ \\
\hline \multicolumn{3}{|l|}{ *p<0,05 по сравнению с регистром ОНМК-ЛД } \\
\hline \multicolumn{3}{|c|}{ ауказано общее число больных с данным показанием к назначению Лп } \\
\hline \multicolumn{3}{|c|}{ Терапия на дату референсного визита указана по совокупности назначений на данном визите, а также последних назначений терапевта, кардиолога, невролога за предшествующие 12 мес } \\
\hline \multicolumn{3}{|c|}{$\begin{array}{l}\text { ЛП - лекарственный препарат, ИАПФ - ингибиторы ангиотензинпревращающего фермента, БРА - блокаторы рецепторов ангиотензина, ХСН - хроническая сердечная недостаточность, } \\
\text { ПИКС - постинфарктный кардиосклероз, } \beta \text {-АБ - бета-адреноблокаторы, ИБС - ишемическая болезнь сердца, ОНМК - острое нарушение мозгового кровообращения, } \\
\text { ФП - фибрилляция предсердий }\end{array}$} \\
\hline
\end{tabular}

наблюдения после развития референсного ОНМК у больных обоих анализируемых регистров.

До развития референсного ОНМК у больных регистра ОНМК-ПО по сравнению с регистром ОНМК-ЛД значимо чаще назначались ИАПФ/БРА и бета-адреноблокаторы ( $\beta$-АБ) при ХСН, статины при ИБС и антиагреганты при ИБС без ФП. На амбулаторном этапе в первые 6 мес после референсного ОНМК у больных регистра ОНМК-ПО значимо чаще были назначены ИАПФ/БРА при ХСН, $\beta$-АБ при ХСН, статины при ИБС, статины при ОНМК, антикоагулянты при ФП и антиагреганты при ИБС без ФП.

В регистрах ОНМК-ЛД и ОНМК-ПО на этапе до референсного ОНМК в наибольшей степени соответствовала клиническим рекомендациям частота назначения ИАПФ/БРА при ХСН, в наименьшей - антикоагулянтов при ФП и статинов при ИБС. После референсного ОНМК также более благоприятной была ситуация с назначением ИАПФ/БРА при ХСН, а наименее благоприятной - с назначением антикоагулянтов при $Ф П$.

у больных регистра ОНМК-ЛД в первые 6 мес наблюдения после ОНМК и на референсном визите (в среднем через 3,5 года после ОНМК) была сопоставлена в динамике частота назначения прогноз-модифицирующей терапии (табл. 3).

Частота назначения всех анализируемых вариантов прогноз-модифицирующей медикаментозной терапии по поводу ССЗ была более высокой на дату референсного визита, по сравнению с первыми 6 мес на- блюдения в постинсультном периоде (что отражает улучшение качества медикаментозного лечения за период между этими этапами). Наиболее выраженным было повышение частоты назначения пероральных антикоагулянтов (ОАК) при ФП (в 5,9 раза), статинов при ИБС (в 2,3 раза) и статинов при ОНМК (в 2,3 раза). В наименьшей степени изменилась частота назначения больным с ИМ в анамнезе: $\beta$-АБ (в 1,2 раза), антиагрегантов (в 1,2 раза) и статинов (в 1,3 раза).

У пациентов с ФП за период 1,4 года, разделяющий в сравниваемых регистрах средние значения даты референсного визита в поликлинику, структура назначения антитромботической терапии изменилась в положительную сторону, но совершенно недостаточно соответствовала клиническим рекомендациям (рис. 1). Частота назначения ОАК составила всего 9\% и 15\%. Преобладало назначение препаратов ацетилсалициловой кислоты - 45\% и 59\% без сочетания с ОАК, а также 5\% и 3\% случаев в виде неоправданного назначения ее препаратов в комбинации с ОАК. В $41 \%$ и 23\% случаев антитромботическая терапия не проводилась.

По данным, представленным в табл. 4, на этапе отдаленного наблюдения частота приема пациентами лекарственных препаратов (ЛП) проанализированных 11 групп существенно не отличалась в сопоставляемых регистрах, за исключением более частого назначения статинов больным регистра ОНМК-ПО $(p<0,05)$. Среднее число принимаемых ЛП у больных регистра ОНМК-ЛД составило 2,04, а в регистре ОНМК-ПО - 2,55, т.е. в 1,25 раза больше. 


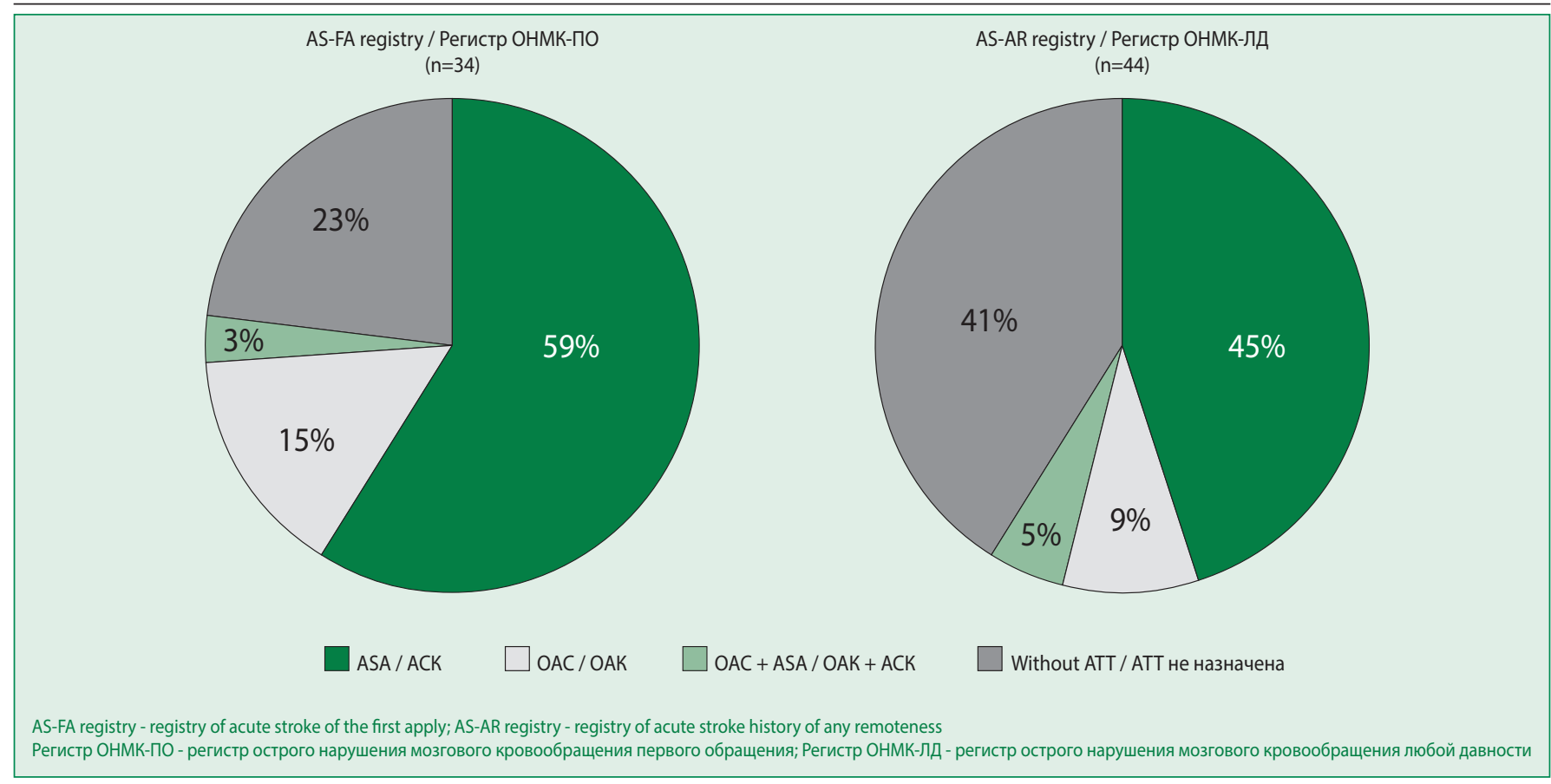

Figure 1. Prescription of antithrombotic therapy to patients with a combination of atrial fibrillation and the history of acute stroke (according to the visit of inclusion in the registers)

Рисунок 1. Назначение антитромботической терапии больным с сочетанием фибрилляции предсердий и перенесенного ОНМК (по данным визита включения в регистры)

На этапе отдаленного проспективного наблюдения (табл. 5) у больных регистра ОНМК-ПО статины назначались чаще в 2,1 раза, в т.ч и при сочетании перенесенного ОНМК и ИБС в 2,6 раза $(p<0,05)$, однако, недостаточно часто (в 40\% случаев). Достоверных различий частоты назначения других ЛП не выявлено. Доля соответствия показаниям назначенной прогностически значимой медикаментозной терапии на эта- пе отдаленного проспективного наблюдения у больных регистра ОНМК-ПО была в среднем в 1,4 раза выше, чем в регистре ОНМК-ЛД (33,8\% и 47,7\%, соответственно). Таким образом, у больных с более давним перенесенным ОНМК имелась тенденция к сохранению менее оптимальной медикаментозной терапии.

В табл. 6 для основных медикаментозных назначений, влияющих на прогноз, представлены дан-

Table 4. Frequency of use of the main groups of drugs by patients included in the acute stroke registries at the stage of long-term follow-up (by results of contacts)

Таблица 4. Частота приема основных групп лекарственных препаратов больными, включенными в регистры ОНМК, на этапе отдаленного наблюдения (по результатам контакта)

\begin{tabular}{|c|c|c|}
\hline Группа лекарственных препаратов & Регистр ОНМК-ЛД (n=131) & Регистр ОНМК-ПО (n=75) \\
\hline ИАПФ / БРА, \% & 55,8 & 64,1 \\
\hline Бета-адреноблокаторы, \% & 24,6 & 33,3 \\
\hline Антагонисты кальция, \% & 15,9 & 17,9 \\
\hline Диуретики, \% & 23,9 & 23,1 \\
\hline Статины, \% & 16,0 & $41,3^{*}$ \\
\hline Оральные антикоагулянты, \% & 2,2 & 5,1 \\
\hline Антиагреганты, \% & 46,4 & 48,7 \\
\hline Сердечные гликозиды, \% & 5,8 & 6,4 \\
\hline Ноотропные препараты, \% & 13,0 & 14,1 \\
\hline Антиоксиданты, \% & 0 & 13,0 \\
\hline Полипептиды, \% & 0,7 & 2,6 \\
\hline \multicolumn{3}{|l|}{ *р<0,05 по сравнению с регистром ОНМК-ЛД } \\
\hline \multicolumn{3}{|c|}{ ИАПФ - ингибиторы ангиотензинпревращающего фермента, БРА - блокаторы рецепторов ангиотензина } \\
\hline \multicolumn{3}{|c|}{ Среднее число принимаемых ЛП у больных регистра ОНМК-ЛД составило 2,04, а в регистре ОНМК-ПО - 2,55, т.е. в 1,25 раза больше } \\
\hline
\end{tabular}


Table 5. Frequency of prognosis-modifying drug prescriptions for cardiovascular diseases in patients of acute stroke registries of any remoteness and the first apply to the out-patient clinic at the stage of prospective observation

Таблица 5. Частота назначения по поводу СС3 лекарственных препаратов, влияющих на прогноз, больным регистров ОНМК-ЛД и ОНМК-ПО на этапе проспективного наблюдения

\begin{tabular}{|c|c|c|}
\hline \multirow[t]{2}{*}{ Группа ЛП и показания к их назначению } & \multicolumn{2}{|c|}{ Назначения на этапе проспективного наблюдения } \\
\hline & ОНМК-ЛД (n=131) & OHMK-ПО (n=75) \\
\hline ИАПФ/БРА при ХСН, \% & 55,4 & 70,8 \\
\hline ИАПФ при ПИКС, \% & 23,5 & 45,5 \\
\hline$\beta$-АБ при ХСН, \% & 27,2 & 39,6 \\
\hline ק-АБ при ПИКС, \% & 23,5 & 27,3 \\
\hline Статины при ИБС, \% & 18,7 & $40,0^{*}$ \\
\hline Статины при ПИКС, \% & 23,5 & 45,5 \\
\hline Статины при ОНМК, \% & 16,0 & $41,3^{*}$ \\
\hline Антикоагулянты при ФП, \% & 8,7 & 23,5 \\
\hline Антиагреганты при ИБС без ФП, \% & 53,6 & 65,5 \\
\hline Антиагреганты при ПИКС без ФП, \% & 58,3 & 28,6 \\
\hline ИАПФ при ОНМК, \% & 47,3 & 53,3 \\
\hline \multicolumn{3}{|c|}{ *р<0,05 по сравнению с регистром ОНМК-лД } \\
\hline \multicolumn{3}{|c|}{$\begin{array}{l}\text { ЛП - лекарственный препарат, ИАПФ - ингибиторы ангиотензинпреврващающего ферментт, БРА - блокаторы рецепторов ангиоотензина, ХСН - хроническая сердечная недостаточность, } \\
\text { ПиКС - постинфарктный кардиосклероз, } \beta \text {-АБ - бета-адреноблокаторы, ИБС - ишемическая болезнь сердца, ОНМК - острое нарушение мозгового кровообращения, } \\
\text { ФП - фибрилляция предсердий }\end{array}$} \\
\hline \multicolumn{3}{|c|}{ Средняя длительность проспективного наблюдения после визита включения у больных регистра ОНМК-лд - 36 мес, регистра ОНМК-по - 24 мес } \\
\hline
\end{tabular}

Table 6. Proportion of patients with continued and newly prescribed drug therapy among patients enrolled in acute stroke registries at the stage of remote prospective observation (\%)

Таблица 6. Доля лиц с продолжаемой и вновь назначенной медикаментозной терапией среди больных, включенных в регистры ОНМК на этапе отдаленного проспективного наблюдения (\%)

\begin{tabular}{|c|c|c|c|c|}
\hline \multirow[t]{2}{*}{ Группа ЛП и показания к их назначению } & \multicolumn{2}{|c|}{ Продолжена терапия } & \multicolumn{2}{|c|}{ Впервые назначены ЛП } \\
\hline & Регистр ОНМК-ЛД & Регистр ОНМК-ПО & Регистр ОНМК-ЛД & Регистр ОНМК-ПО \\
\hline ИАПФ/БРА при ХСН & 62,7 & 76,4 & 37,3 & 23,6 \\
\hline ИАПФ при ПИКС & 25 & 80 & 75 & 20 \\
\hline$\beta$-АБ при ХСН & 68 & 78,9 & 32 & 21,1 \\
\hline$\beta$-АБ при ПИКС & 25 & $100^{*}$ & 75 & $0^{*}$ \\
\hline Статины при ИБС & 41,2 & $83,3^{*}$ & 58,8 & $16,7^{*}$ \\
\hline Статины при ПИКС & 25 & 60 & 75 & 40 \\
\hline Статины при ОНМК & 52,4 & $90,3^{*}$ & 47,6 & $9,7^{*}$ \\
\hline Антикоагулянты при ФП & 100 & 75 & 0 & 25 \\
\hline Антиагреганты при ИБС без ФП & 54,1 & 78,9 & 45,9 & 21,1 \\
\hline Антиагреганты при ПИКС без ФП & 28,9 & 100 & 71,1 & 0 \\
\hline ИАПФ при ОНМК & 59,7 & 77,5 & 40,3 & 22,5 \\
\hline \multicolumn{5}{|l|}{ *p<0,05 по сравнению с регистром ОНМК-ЛД } \\
\hline \multicolumn{5}{|c|}{$\begin{array}{l}\text { ЛП - лекарственный препарат, ИАПФ - ингибиторы ангиотензинпревращающего фермента, БРА - блокаторы рецепторов ангиотензина, ХСН - хроническая сердечная недостаточность, } \\
\text { пиКС - постинфарктный кардиосклероз, } \beta \text {-АБ - бета-адреноблокаторы, ИБС - ишемическая болезнь сердца, ОНМК - острое нарушение мозгового кровообращения, } \\
\text { ФП - фибрилляция предсерддий }\end{array}$} \\
\hline
\end{tabular}

ные этапа отдаленного наблюдения о доле лиц с продолжением лечения, назначенного на визите включения, а также с впервые назначенной терапией. В регистре ОНМК-ПО был достоверно выше процент сохранения назначенной терапии статинами, в т.ч. при ИБС, а также терапии $\beta$-АБ при ПИКС. В целом в регистрах ОНМК-ЛД и ОНМК-ПО доля прогностически значимых медикаментозных назначений на этапе отдаленного наблюдения, соответствующих таковым на этапе включения, составила 56\% и $81 \%$, т.е. была на этапе отдаленного наблюдения в 1,4 раза больше в регистре ОНМК-ПО. Доля случаев впервые начатой прогностически значимой терапии составила 44\% и 19,4\%, соответственно, от всех случаев назначения на этапе отдаленного наблюдения. Если за 100\% принять все случаи прогностически значимых назначений на этапе включения у пациентов с наличием данных на обоих этапах, то доля преемственности назначений в 
Table 7. The frequency of prognosis-modifying drug prescriptions for cardiovascular diseases at the stages of inclusion in the registry of acute stroke of any remoteness and after 3 years of prospective observation

Таблица 7. Частота назначения по поводу ССЗ лекарственных препаратов, влияющих на прогноз, на этапах включения в регистр ОНМК-ЛД и через 3 года проспективного наблюдения (\%)

\begin{tabular}{|c|c|c|}
\hline Группа ЛП и показания к их назначению & $\begin{array}{c}\text { Назначения на этапе включения } \\
\text { в регистра }\end{array}$ & $\begin{array}{l}\text { Назначения на этапе проспективного } \\
\text { наблюдения (36 мес после включения) } \\
\qquad \mathrm{n}(\%) \mathrm{n}=131\end{array}$ \\
\hline ИАПФ/БРА при ХСН (n=92) & 57,6 & 55,4 \\
\hline ИАПФ при ПИКС $(n=17)$ & 35,3 & 23,5 \\
\hline 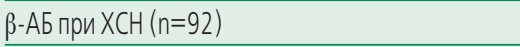 & 34,8 & 27,2 \\
\hline$\beta-А Б$ при ПИКС (n=17) & 35,3 & 23,5 \\
\hline Статины при ИБС ( $n=91)$ & 30,8 & $18,7^{*}$ \\
\hline Статины при ПИКС ( $n=17)$ & 29,4 & 23,5 \\
\hline Статины при ОНМК (n=131) & 26,7 & $16,0 *$ \\
\hline Антикоагулянты при ФП (n=23) & 17,4 & 8,7 \\
\hline Антиагреганты при ИБС без ФП (n=69) & 50,7 & 53,6 \\
\hline Антиагреганты при ПИКС без ФП (n=12) & 41,7 & 58,3 \\
\hline ИАПФ при ОНМК (n=131) & 45,8 & 47,3 \\
\hline \multicolumn{3}{|c|}{ *p<0,05 по сравнению с противоположной группой } \\
\hline \multicolumn{3}{|c|}{ ауказана частота (\%) назначений ЛП у больных с наличием данных на этапах включения и отдаленного наблюдения } \\
\hline \multicolumn{3}{|c|}{$\begin{array}{l}\text { ЛП - лекарственный препарат, ИАПФ - ингибиторы ангиотензинпревращающего фермента, БРА - блокаторы рецепторов ангиотензина, ХСН - хроническая сердечная недостаточность, } \\
\text { ПИКС - постинфарктный кардиосклероз, В-АБ - бета-адреноблокаторы, ИБС - ишемическая болезнь сердца, ОНМК - острое нарушение мозгового кровообращения, } \\
\text { ФП - фибрилляция предсердий }\end{array}$} \\
\hline
\end{tabular}

Table 8. The frequency of prognosis-modifying drug prescriptions for cardiovascular diseases at the stages of inclusion in the registry of acute stroke of the first apply to the out-patient clinic and after 2 years of prospective observation (\%)

Таблица 8. Частота назначения по поводу СС3 лекарственных препаратов, влияющих на прогноз на этапах включения в регистр ОНМК-ПО и через 2 года проспективного наблюдения (\%)

\begin{tabular}{|c|c|c|}
\hline Группа ЛП и показания к их назначениюа & $\begin{array}{l}\text { Назначения на этапе включения } \\
\text { в регистр }\end{array}$ & $\begin{array}{l}\text { Назначения на этапе проспективного } \\
\text { наблюдения ( } 24 \text { мес после включения) }\end{array}$ \\
\hline ИАПФ/БРА прИ ХСН (n=48) & 68,8 & 70,8 \\
\hline ИАПФ при ПИКС (n=11) & 45,5 & 45,5 \\
\hline 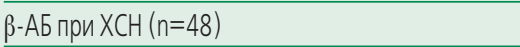 & 41,7 & 39,6 \\
\hline 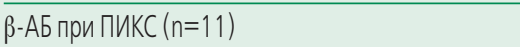 & 54,6 & 27,3 \\
\hline Статины при ИБС (n=45) & 60,0 & $40,0^{*}$ \\
\hline Статины при ПИКС (n=11) & 54,6 & 45,5 \\
\hline Статины при ОНМК (n=75) & 61,3 & $41,3^{*}$ \\
\hline Антикоагулянты при ФП (n=17) & 29,4 & 23,5 \\
\hline Антиагреганты при ИБС без ФП (n=29) & 62,1 & 65,5 \\
\hline Антиагреганты при ПИКС без ФП (n=7) & 42,9 & 28,6 \\
\hline ИАПФ при ОНМК (n=75) & 53,3 & 53,3 \\
\hline \multicolumn{3}{|c|}{ ауказана частота (\%) назначений ЛП у больных с наличием данных на этапах как включения, так и отдаленного наблюдения } \\
\hline \multicolumn{3}{|c|}{ *р<0,05 по сравнению спротивоположной группой } \\
\hline \multicolumn{3}{|c|}{$\begin{array}{l}\text { ЛП - лекарственный препарат, ИАПФ - ингибиторы ангиотензинпревращающего фермента, БРА - блокаторы рецепторов ангиотензина, ХСН - хроническая сердечная недостаточность, } \\
\text { ПИКС - постинфарктный кардиосклероз, ३-АБ - бета-адреноблокаторы, ИБС - ишемическая болезнь сердца, ОНМК - острое нарушение мозгового кровообращения, } \\
\text { ФП - фибрилляция предсердий }\end{array}$} \\
\hline
\end{tabular}

отдаленном периоде составила 49\% и 70\% (в среднем $58 \%$ ).

У лиц с наличием данных о медикаментозной терапии как на визите включения, так и в отдаленном периоде наблюдения, сопоставлена в динамике частота прогностически значимых медикаментозных назначений (табл. 7 и 8). В регистрах ОНМК-лД и ОНМК-ПО достоверные различия частоты прогностически значимого назначения ЛП на этапе включения в регистр и его соблюдения на этапе отделенного наблюдения были выявлены только для статинов при ОНМК (в регистре ОНМК-ПО снизилась за время наблюдения в 1,7 и 1,5 раза, соответственно), в т.ч. у больных с наличием ИБС (снизилась в 1,6 и 1,5 раза). 
Table 9. Adherence to drug therapy of patients included in the acute stroke registries (proportion of patients with a Morisky-Green score from 0 to 4 , in \%)

Таблица 9. Приверженность к медикаментозной терапии больных, включенных в регистры ОНМК (доля лиц с числом баллов по шкале Мориски-Грина от 0 до 4; в \%)

\begin{tabular}{lcc}
\hline Число баллов по шкале Мориски-Грина & ОНМК-лД $(\mathrm{n}=130)$ & ОНМК-ПО $(\mathrm{n}=75)$ \\
\hline 0 & 33,8 & $13,3^{*}$ \\
\hline 1 & 15,4 & 8,0 \\
\hline 2 & 22,3 & 12,0 \\
\hline 3 & 10,8 & 16,0 \\
\hline 4 & 17,7 & $50,7^{*}$ \\
\hline
\end{tabular}

Данные о приверженности пациентов медикаментозному лечению приведены в табл. 9. Доля лиц, приверженных медикаментозной терапии (4 балла по шкале Мориски-Грина), была в 2,9 раз большей в регистре ОНМК-ПО, чем в регистре ОНМК-ЛД ( $<<0,0001)$. Доля пациентов с низкой приверженностью (0-1 балл) в регистре ОНМК-ЛД превышала таковую в регистре ОНМК-ПО в 2,3 раза ( $p=0,001)$. На более высокую приверженность медикаментозной терапии пациентов, включенных в регистр ОНМК-ПО, указывает также большее среднее число баллов по шкале Мориски-Гри-

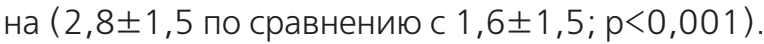

\section{Обсуждение}

В настоящей публикации представлены результаты сравнительной оценки назначенной и реально принимаемой медикаментозной терапии у больных, включенных на пилотном этапе исследования РЕГИОН в амбулаторные регистры ОНМК-ЛД и ОНМК-ПО. Сопоставление данных двух амбулаторных регистров, в которых давность развития референсного ОНМК у пациентов различалась в среднем на 4,8 года, а визитов включения - на 1,4 года, позволило выявить и предварительно оценить улучшение качества назначенной и реально принимаемой лекарственной терапии в одной из поликлиник за этот период, а также влияние срока от развития ОНМК на качество назначенной медикаментозной терапии.

Улучшение качества медикаментозного лечения характеризуется большей частотой соответствия клиническим рекомендациям назначения прогноз-модифицирующей медикаментозной терапии (в т.ч. ИАПФ и $\beta$-АБ при ХСН и ПИКС, статинов при ИБС и при перенесенных ИМ и ОНМК, антикоагулянтов при ФП). Однако, качество амбулаторного медикаментозного лечения больных, перенесших OHMK, остается еще совершенно недостаточным, в т.ч. это касается частоты назначения статинов при перенесенных OHMK - 16,0\% и 41,3\% и ИМ - 23,5\% и 45,5\%.

Частота наличия ФП, являющейся фактором риска развития ОНМК, составила в регистрах ОНМК-ЛД и
ОНМК-ПО 22,5\% и 29,6\% случаев. Однако частота назначения антикоагулянтов была совершенно недостаточной (от 9,0\% и 14,7\% перед развитием ОНМК до 8,7\% и 23,5\% на этапе отдаленного амбулаторного наблюдения). Таким образом, повышение частоты назначения антикоагулянтов при ФП до должных значений (т.е. более чем в 4 раза) является важным резервом в повышении эффективности первичной и вторичной профилактики ОНМК в реальной поликлинической практике.

Полученные данные сходны с результатами, полученными в исследованиях ЛИС-2, РЕКВАЗА и РЕГИОН (Москва) [15, 16,25-27]. Кроме того, недостаточное качество медикаментозной вторичной профилактики OHМК было также отмечено в ряде иностранных регистров мозгового инсульта $[4,5]$.

На этапе отдаленного наблюдения соответствие проводимой медикаментозной терапии клиническим рекомендациям у больных регистра ОНМК-лД было меньшим, чем в регистре ОНМК-ПО (хотя опрос пациентов проводился в один и тот же период времени), В т.ч. терапия статинами проводилась в 2,6 раза реже. Это, в частности, отражает инертность назначенного не оптимального медикаментозного лечения. Кроме того, у пациентов с более давним перенесенным ОНМК была меньше и приверженность лечению.

В период отдаленного наблюдения лишь около 60\% назначений, сделанных за 2-3 года до этого, продолжали выполняться. Одной из причин данного факта является то, что менее половины пациентов были привержены лечению. Однако значительная часть прогностически значимых назначений пациентам, включенным в регистры ОНМК-ЛД и ОНМК-ПО, была осуществлена впервые за период наблюдения (44\% и 19\%). Поэтому в совокупности частота должных медикаментозных назначений изменилась умеренно. Лишь частота назначения статинов достоверно снизилась (в 1,7 и 1,5 раза).

Полученные результаты носят предварительный характер, т.к. отражают данные только одной из трех поликлиник, которые задействованы в создании амбу- 
латорных регистров больных, перенесших ОНМК. Однако и они, с нашей точки зрения, дают очень важную статистически значимую информацию, которая будет дополнена и более детально проанализирована по окончании основного этапа исследования.

\section{Заключение}

Результаты пилотного этапа исследования РЕГИОН (амбулаторные регистры ОНМК-ЛД и ОНМК-ПО) показали, что качество назначенной медикаментозной терапии пациентам в поликлинике, особенно в период до развития мозгового инсульта, является недостаточным. Однако сравнение данных, полученных в регистрах ОНМК-ЛД и ОНМК-ПО, позволяет сделать предварительный вывод о том, что за 5-летний период, разделяющий, в среднем, время развития ОНМК в этих регистрах, качество лечения пациентов значительно улучшилось, хотя и в недостаточной степени, В частности, возросла частота соответствия назначения прогноз-модифицирующей медикаментозной терапии клиническим рекомендациям (в т.ч. статинов, антиагрегантов, ан-

\section{References / Литература}

1. Benjamin E.J., Blaha M.J., Chiuve S.E., et al. Heart Disease and Stroke Statistics-2017 Update: A Report From the American Heart Association. Circulation. 2017;135(10):e146-e603.

2. Demographic Yearbook of Russia, 2015. Statistical Yearbook. Moscow: Rosstat; 2015. (In Russ.) [Дeмографический ежегодник России 2015. Статистический сборник. Москва: Росстат; 2015]

3. Meschia J.F., Bushnell C., Boden-Albala B., et al. Guidelines for the Primary Prevention of Stroke. Stroke. 2014;45(12):3754-832.

4. 2016 European Guidelines on cardiovascular disease prevention in clinical practice. Eur Heart J. 2016;37:2315-81

5. Kernan W.N., Ovbiagele B., Black H.R., et al. Guidelines for the Prevention of Stroke in Patients With Stroke and Transient Ischemic Attack. Stroke. 2014;45(7):2160-236.

6. Bangalore S., Schwamm L., Smith E.E., et al. Secondary prevention after ischemic stroke or transient ischemic attack. Get With the Guidelines-Stroke Steering Committee and Investigators. The American Journal of Medicine. 2014;127(8):728-38

7. Smith E.E., Saver J.L., Alexander D.N., et al. Clinical Performance Measures for Adults Hospitalized With Acute Ischemic Stroke: Performance Measures for Healthcare Professionals From the American Heart Association/American Stroke Association. Stroke. 2014;45(11):3472-98.

8. Winstein C.J., Stein J., Arena R., et al. Guidelines for Adult Stroke Rehabilitation and Recovery. Stroke. 2016;47(6):e98-e169.

9. Lenti L., Bereczki D., Brainin M., et al. Stroke care in the central Eastern Europe: current problems and call for action. International Journal of Stroke. 2013;8(5):365-73

10. Yusuf S., Islam S., Chow C.K., et al. Use of secondary prevention drugs for cardiovascular disease in the community in high-income, middle-income, and low-income countries (the PURE Study): a prospective epidemiological survey. Lancet. 2011;378(9798):1231-43.

11. Smith E.E., Saposnik G., Biesseet G.J., et al. Prevention of Stroke in Patients With Silent Cerebrovascular Disease: A Scientific Statement for Healthcare Professionals From the American Heart Association/American Stroke Association. Stroke. 2017;48:e44-e71.

12. Shi G.M., Zhang Y.D., Geng C., et al. Nanjing First Hospital Stroke Registry Investigators. Profile and 1-Year Outcome of Ischemic Stroke in East China: Nanjing First Hospital Stroke Registry. Journal of Stroke and Cerebrovascular Diseases. 2016;25(1):49-56.

13. Amarenco P., LavallOe P.C., Labreuche J., et al. TIAregistry. org Investigators. One-Year Risk of Stroke after Transient Ischemic Attack or Minor Stroke. The New England Journal of Medicine. 2016;374(16):1533-42.

14. Ogawa H., Senoo K., An Y., et al. Clinical Features and Prognosis in Patients with Atrial Fibrillation and Prior Stroke: Comparing the Fushimi and Darlington AF Registries. EBioMedicine. 2017;18:199-203.

15. Boytsov S.A., Martsevich S.Yu., Ginzburg M.L., et al. Luberetskiy study of the mortality of patients who underwent cerebral stroke or transient ischemic attack (LIS-2). Design and evaluation of drug therapy. Rational Pharmacotherapy in Cardiology. 2013;9(2):114-22. (In Russ.) [Бойцов C.А., Марцевич С.Ю., Гинзбург М.Л., и др. Люберецкое исследование смертности больных, перенесших мозговой инсульт или транзиторную ишемическую атаку (ЛИС-2). Дизайн и оценка лекарственной терапии. Рациональная Фармакотерапия в Кардиологии. 2013;9(2):114-22]. тикоагулянтов). Тем не менее, медикаментозная терапия, реально принимаемая пациентами на этапе отдаленного наблюдения, не в полной мере соответствует прогностически значимым назначениям лекарственных препаратов, сделанных врачами поликлиники. Общее число назначений на отдаленном этапе наблюдения в регистрах ОНМК-ЛД и ОНМК-ПО составили соответственно только $56 \%$ и $81 \%$ от исходного, а новые назначения составляли 44\% и 19\%, соответственно. Одной из причин этого является недостаточная приверженность пациентов лечению, из которых приверженными были лишь 17,7\% и 50,7\% опрошенных.

Конфликт интересов. Научный грант на выполнение исследования предоставлен компанией «Пфайзер», что не отразилось на результатах и собственном мнении авторов.

Disclosures. Research grant for the study is provided by Pfizer company, which did not affect the results and own opinion of the authors.
16. Boytsov S.A., Lukyanov M.M., Yakushin S.S., et al. The registry of cardiovascular diseases (REQUAS): diagnosis, combined cardiovascular pathology, concomitant diseases and treatment in conditions of real outpatient and polyclinic practice. Kardiovaskulyarnaya Terapiya i Profilaktika. 2014;6:44-50. (In Russ.) [Бойцов С.А., Лукьянов М.М., Якушин С.С. и др. Регистр кардиоваскулярных заболеваний (РЕКВАЗА): диагностика, сочетанная сердечно-сосудистая патология, сопутствующие заболевания и лечение в условиях реальной амбулаторно-поликлинической практики. Кардиоваскулярная Терапия и Профилактика. 2014;6:44-50]

17. You J.J., Singer D.E., Howard P.A., et al. Antithrombotic Therapy for Atrial Fibrillation. Antithrombotic Therapy and Prevention of Thrombosis, 9th ed: American College of Chest Physicians Evidence-Based Clinical Practice Guidelines. Chest. 2012;141(Suppl):e531S-e575S.

18. Jiang Y., Yang X., Li Z., et al. Persistence of secondary prevention medication and related factors for acute ischemic stroke and transient ischemic attack in China. Neurological Research. 2017;19:1-6.

19. Andersson T., Magnuson A., Bryngelsson I.L., et al. Patients with atrial fibrillation and outcomes of cerebral infarction in those with treatment of warfarin versus no warfarin with references to $\mathrm{CHA}_{2} \mathrm{DS}_{2}$-VASc score, age and sex - A Swedish nationwide observational study with 48433 patients. PLoS One. 2017:12(5):e0176846.

20. Macha K., Volbers B., Bobinger T., et al. Early Initiation of Anticoagulation with Direct Oral Anticoagulants in Patients after Transient Ischemic Attack or Ischemic Stroke. Journal of Stroke and Cerebrovascular Diseases. 2016;25(9):2317-21.

21. Xie W., Zheng F., Zhong B., et al. Long-Term Antiplatelet Mono- and Dual Therapies After Ischemic Stroke or Transient Ischemic Attack: Network Meta-Analysis. Journal of the American Heart Association. 2015; 4(8):e002259.

22. Niu P.P., Guo Z.N., Jin H., et al. Antiplatelet regimens in the long-term secondary prevention of transient ischaemic attack and ischaemic stroke: an updated network meta-analysis. BMJ Open. 2016;6(3):e009013.

23. Geary L., Aronius J., Wettermark B., et al. Sociodemographic factors are associated with utilisation of statins after ischaemic stroke/TIA. International Journal of Clinical Practice. 2017;71(3-4).

24. Katsanos A.H., Filippatou A., Manios E., et al. Intensity of Blood Pressure Reduction and Secondary Stroke Prevention: A Systematic Review and Meta-regression Analysis of Randomized Clinical Trials. Hypertension. 2017;69:171-9.

25. Suvorov A.Yu., Martsevich S.Yu., Kutishenko N.P., et al. Evaluation of compliance with modern clinical recommendations of cardiovascular therapy aimed at improving outcomes in patients after a stroke (according to the LIS-2 registry). Rational Pharmacotherapy in Cardiology. 2015;11(3):247-52. (In Russ.) [Суворов А.Ю., Марцевич С.Ю., Кутишенко Н.П. и др. Оценка соответствия современным клиническим рекомендациям сердечно-сосудистой терапии, направленной на улучшение исходов у пациентов после перенесенного инсульта (по данным регистра ЛИС-2). Рациональная Фармакотерапия в Кардиологии. 2015;11(3):247-52].

26. Suvorov A. Yu., Martsevich S.Yu., Kutishenko N.P. Evaluation of the quality of therapy in the registries of acute cerebral circulation disorders. Foreign experience, the prospects of Russia. Kardiovaskulyarnaya Terapiya i Profilaktika. 2014; 13 (4): 81-6. (In Russ.) [Суворов А.Ю., Марцевич С.Ю., Кутишенко Н.П. Оценка качества терапии в регистрах острого нарушения мозгового кровообращения. Зарубежный опыт, перспективы России. Кардиоваскулярная Терапия и Профилактика. $2014 ; 13(4): 81-6]$. 
27. Boytsov S.A., Martsevich S.Yu., Kutishenko N.P., et al. The Study "Register of Patients after Acute Stroke (REGION)". Part 1. Hospital Prospective Register of Patients after Acute Stroke (According to the Results of the Pilot Phase of the Study). Rational Pharmacotherapy in Cardiology. 2016; 12 (6): 64553. (In Russ.) [Бойцов С.А., Марцевич С.Ю., Кутишенко Н.П., и др. Исследование "РЕГИстр больных, перенесших Острое Нарушение мозгового кровообращения (РЕГИОН)". Часть 1. Госпитальный проспективный регистр больных, перенесших острое нарушение мозгового кровообращения (по результатам пилотного этапа исследования). Рациональная Фармакотерапия в Кардиологии. 2016;12(6):645-53].
28. Boytsov S.A., Loukyanov M.M., Yakushin S.S., et al. The Study "Register of Patients after Acute Stroke (REGION)". Part 2. Outpatient Prospective Register of Patients after Acute Stroke (According to the Results of the Pilot Phase of the Study). Rational Pharmacotherapy in Cardiology. 2017;13(1):4-17. (In Russ.) [Бойцов С.А., Лукьянов М.М., Якушин С.С. и др. Исследование "РЕГИстр больных, перенесших Острое Нарушение мозгового кровообращения (РЕГИОН)". Часть 2. Амбулаторный проспективный регистр больных, перенесших острое нарушение мозгового кровообращения (по результатам пилотного этапа исследования). Рациональная Фармакотерапия в Кардиологии. 2017;13(1):4-17].

29. Morisky D.E., Green L.W., Levine D.M. Concurrent and predictive validity of a self-reported measure of medication adherence. Med Care. 1986;24(1):67-74.

Сведения об авторах:

Бойцов Сергей Анатольевич - Д.м.н., профессор, член-корреспондент РАН, руководитель отдела клинической кардиологии и молекулярной генетики, ГНИЦПМ

Лукьянов Михаил Михайлович - К.М.Н., В.Н.С. отдела клинической кардиологии и молекулярной генетики, ГНИЦПМ якушин Сергей Степанович - д.м.Н., профессор, заведующий кафедрой госпитальной терапии РязГМУ

Марцевич Сергей Юрьевич - Д.м.Н., профессор, руководитель отдела профилактической фармакотерапии ГНИЦПМ

Стаховская Людмила Витальевна - д.м.Н., профессор кафедры фундаментальной и клинической неврологии и нейрохирургии, РНИМУ им. Н.И. Пирогова

Воробьев Александр Николаевич - К.м.Н., ассистент кафедры госпитальной терапии РязГМУ

Загребельный Александр Васильевич - К.М.Н., С.Н.С. отдела профилактической фармакотерапии, ГНИЦПМ

Козминский Александр Николаевич - ассистент центра симуляционного обучения РязГМУ

Мосейчук Ксения Анатольевна - аспирант кафедры госпитальной терапии РязГМУ

Переверзева Кристина Геннадьевна - К.М.Н., ассистент кафедры госпитальной терапии РязГМУ

Правкина Екатерина Алексеевна - К.м.Н., ассистент кафедры госпитальной терапии РязГМУ

Белова Екатерина Николаевна - программист лаборатории биостатистики отдела эпидемиологии хронических неинфекционных заболеваний, ГНИЦПМ

Кляшторный Владислав Георгиевич - К.б.Н., Н.С. лаборатории биостатистики ГНИЦПМ

Кудряшов Егор Викторович - программист лаборатории биостатистики отдела эпидемиологии хронических неинфекционных заболеваний, ГНИЦПМ

Окшина Елена Юрьевна - К.М.Н., С.Н.С. отдела клинической кардиологии и молекулярной генетики, ГНИЦПМ

Деев Александр Дмитриевич - К.ф-м.н., руководитель лаборатории биостатистики отдела эпидемиологии хронических неинфекционных заболеваний, ГНИЦПМ 